\title{
Effect of environmental enrichment and composition of the social group on the behavior, welfare, and relative brain weight of growing rabbits
}

\author{
Thais F.M. Bozicovich, Ana Silvia A.M.T. Moura*, Simone Fernandes, Aline A. Oliveira, \\ Edson R. Siqueira Siqueira \\ Departamento de Produção Animal, Faculdade de Medicina Veterinária e Zootecnia, São Paulo State University, UNESP, CEP: 18618-970, Botucatu, SP, Brazil
}

\section{A R T I C L E I N F O}

\section{Article history:}

Received 19 August 2015

Received in revised form 20 May 2016

Accepted 30 May 2016

Available online 8 June 2016

\section{Keywords:}

Aggressive behavior

Mixed-gender group

Self-grooming

Social interaction

Stereotypes

\begin{abstract}
A B S T R A C T
The objective of the study was to investigate if environmental enrichment and the composition of the social group would affect the behavior and relative brain weight of growing rabbits. Rabbits ( 72 males and 72 females) were assigned to cages with or without enrichment and one of three social groups (males, females, or mixed-gender). Two eucalyptus sticks suspended from the cage ceiling were provided in the enriched cages based on the results of a preliminary trial conducted on growing rabbits $(n=48)$ showing that pieces of wood (Eucalyptus sp, Pinus $s p$ ) or bamboo (Dendrocalamus giganteus) were preferred over PVC pipe ( $\mathrm{P}<0.05)$. Rabbits were exposed to the experimental conditions between six and 11 weeks of age. Behavioral activities were video recorded for $24 \mathrm{~h}$, at 7, 10 and 11 weeks of age. Growth performance was recorded from 42 to 77 days of age, whereas skin wounds and brain weight were recorded at 77 days. At 70 days of age, rabbits in non-enriched cages showed a higher proportion of self-grooming $(P=0.012)$ than those in enriched cages. Enrichment decreased the number of social interactions among rabbits $(P=0.012)$, but increased aggressive behavior $(P=0.007)$. The number of animals showing skin wounds on day 77 was lower $(P=0.006)$ in enriched than in non-enriched cages. The incidence of social interactions was higher $(\mathrm{P}<0.05)$ and of stereotypes was lower $(\mathrm{P}<0.05)$ in mixed-gender groups than in same-sex groups. Female groups showed the lowest incidence of aggressive behavior $(\mathrm{P}<0.05)$. The number of individuals with skin injuries was higher in mixed-gender groups $(\mathrm{P}<0.05)$ than in female groups; male groups were intermediate. Growth performance was unaffected by enrichment or by the composition of social group. Males in enriched cages had heavier brains $(\mathrm{P}<0.05)$ than those in nonenriched cages. Although aggressive behaviors were more frequent, the number of skin wounds on day 77 was lower in rabbits from enriched cages, suggesting improved welfare. Based on the increased frequency of social interactions and decreased incidence of stereotyped behavior, mixed-gender groups should be housed in collective cages from weaning up to 11 weeks of age. However, if the incidence of skin wounds is considered, only females can be housed in same-sex groups. For males, individual cages should be preferred. Whether environmental enrichment induces morphologic changes in male rabbits' brains should be further investigated.
\end{abstract}

(c) 2016 Elsevier B.V. All rights reserved.

\section{Introduction}

Rabbits have been used for decades for intensive lean meat production and also as models in biomedical research such as anti-

\footnotetext{
* Corresponding author.

E-mail addresses: tha_freitas20@hotmail.com (T.F.M. Bozicovich), anamoura@fmvz.unesp.br, asamtmoura@uol.com.br (A.S.A.M.T. Moura), simone.fernandes@fmvz.unesp.br (S. Fernandes), aline_btu@ig.com.br (A.A. Oliveira), ersiqueira@fmvz.unesp.br (E.R.S. Siqueira).
}

body production (Hanly et al., 1995; Grosse-Hovest et al., 2004), lipoproteins and atherosclerosis research (Van Zutphen and Fox, 1977; Korstanje, 2000), cardiovascular physiology research (Bõsze and Houdebine, 2006), ophthalmology and vision research (Gwon 2008; Kang and Grossniklaus, 2011), and more recently, in the development of implant dentistry research (Mapara et al., 2012; Stübinger and Dard, 2013).

Both in rabbit farms and in laboratories, animals are frequently kept in barren cages, generating increasing concern with their welfare (Hansen and Berthelsen, 2000). The welfare of growing rabbits kept in cages depends on whether housing is individual, 
in pairs, or in groups, on group size and stocking density, but also on the quality of the environment (Chu et al., 2004; Verga et al., 2007; Trocino et al., 2014). Physiology, health, reproduction, and production may be used to evaluate stress, but the evaluation of the ethogram represents a key welfare indicator in animals kept in intensive conditions. In rabbits, the normal behavioral repertoire includes foraging and social behaviors, but confinement in barren cages reduces locomotion and may lead to altered social behavior and the development of stereotypies (Morisse and Maurice, 1997; Hansen and Berthelsen, 2000; Verga et al., 2007).

Environmental enrichment can be viewed as any modification of the environment that exerts favorable effects on the animals' behavior and ability to cope with captivity, by stimulating their species-specific needs (Newberry, 1995; Olsson and Dahlborn, 2002). It should improve the behavioral repertoire and reduce the frequency of abnormal behavior. For caged rabbits, environmental enrichment may be accomplished by the provision of social companions, by adding structures that can be used as shelters or resting places, such as boxes or elevated platforms, or by providing additional food objects such as straw, alfalfa cubes or wooden sticks to meet the animals' need for chewing (Jordan et al., 2006).

Using straw as cage enrichment had positive effects on rabbit behavior by increasing the frequency of exploratory activities and decreasing stereotypes and self-grooming (Siloto et al., 2008). Straw on the cage floor, however, may favor feces accumulation and represent a sanitary risk. A "u" shaped wooden structure decreased cage manipulation and interactions with conspecifics, probably because it was used as a shield against unwanted social contact (Buijs et al., 2011). The most commonly used enrichment for growing rabbits is the wooden stick. It was found to improve the welfare of growing rabbits through the reduction of body injuries (Princz et al., 2008).

Despite the body of work regarding rabbit behavior under various environmental conditions, few studies have focused on underlying physiological or physical changes. For example, in rodents and other animal species, the addition of environmental stimuli was found to increase brain weight (Diamond et al., 1964) by enhancing cortical thickness and dendritic ramification (Beaulieu and Colonnier, 1987; Rosenzweig and Bennet, 1996), stimulating neurogenesis in the hippocampus (Kempermann et al., 1997), and improving memory in learning tasks (Van Praag et al., 2000). However, none of the structural or functional changes resulting from environmental enrichment has been investigated in rabbits.

In nature, small groups of one to four male and one to nine female rabbits with a clearly defined hierarchy are common (Trocino and Xiccato, 2006). Social rank orders in these groups are established and maintained by intensive fights (Von Holst et al., 2002). Based on the complex social structure of wild rabbits, domestic animals should be raised in groups both in the reproduction and growth phases (Trocino and Xiccato, 2006; Szendrö and Dalle Zotte, 2011). In rabbit farms, however, breeding males are individually caged due to fighting and breeding females due to competition for nest boxes during late pregnancy and lactation. Fattening rabbits, on the other hand, are kept in collective cages, in which group size depends on cage dimensions (Verga et al., 2007). The EFSA (2005) recommends a minimum of $3500 \mathrm{~cm}^{2}$ available cage floor surface for breeding males and females and at least $625 \mathrm{~cm}^{2}$ individual surface for fatteners with a maximum of $40 \mathrm{~kg}$ live weight $/ \mathrm{m}^{2}$. Nevertheless, this poses a problem when the growing rabbits reach puberty and the risk of aggressive behavior increases, especially among males. The larger and the older the group, the higher the frequency of severe wounds due to fighting (Trocino and Xiccato, 2006). Laboratory rabbits are usually housed in individual cages that are often small and lack any sort of stimuli (Gunn and Morton, 1995; Hansen and Berthelsen, 2000). Space allowances according to the European Council Directive 2010/63/EU are $800 \mathrm{~cm}^{2} /$ rabbit from weaning up to 7 weeks of age and $1200 \mathrm{~cm}^{2} /$ rabbit from 7 to 10 weeks of age. For rabbits over 10 weeks of age, the minimum floor area per animal ranges from 3500 to $5400 \mathrm{~cm}^{2}$ according to body weight.

Previous studies have investigated the effects of housing system (Trocino et al., 2014), group size, cage size, and stocking density (Chu et al., 2004; Princz et al., 2008; Buijs et al., 2011) on the behavior of growing rabbits. However, the potential effects of changes to the composition of the social group on social interaction, aggression and injuries have been largely neglected in rabbits, except for one study which showed no effect of social group composition on behavior (Szendrö et al., 2012).

The objective of the present study was to investigate if environmental enrichment and the composition of social group would affect the behavior, welfare and relative brain weight of growing rabbits. The hypothesis was that an enriched environment would improve the welfare of growing rabbits by stimulating motor activity, investigatory and social behaviors and ultimately influencing brain development. But this response could be dependent on the composition of the social group. To investigate this hypothesis, rabbits were housed with or without enrichment and in one of three social group compositions (males, females, or mixed-gender). Environmental enrichment material was selected based on the results of a preliminary trial conducted on growing rabbits.

\section{Material and methods}

One hundred and ninety-two rabbits from the Botucatu genetic group (Bianospino et al., 2006) were used in two experiments conducted at the UNESP Rabbit Production Unit, located in Botucatu, SP, Brazil. At weaning, at 35 days of age, animals had three digit numbers tattooed in their ears for identification and were housed in an east-west oriented building equipped with commercial wire cages $(0.80 \times 0.60 \times 0.45 \mathrm{~m}$, Gaiolas Londrina, Brazil). The building had plastic adjustable curtains used to control ventilation. Illumination was natural, but four black light bulbs were used during the dark period for behavioral observation or video recording. Local $\left(22^{\circ} 51^{\prime} \mathrm{S}, 48^{\circ} 26^{\prime} \mathrm{W}\right)$ natural photoperiod is approximately $11.5 \mathrm{~h}$ in April, decreasing to $10.5 \mathrm{~h}$ in June (June 21 is the winter solstice) and increasing to $13.5 \mathrm{~h}$ in December (December 21 is the summer solstice). Drinking water and a commercial pelleted feed (Agromix Nutrição Animal, Jaboticabal, Brazil) were provided ad libitum. All the animal procedures were approved under protocol number $011 / 2010$ by the Faculdade de Medicina Veterinária e Zootecnia, UNESP, IACUC on February 10, 2010.

\subsection{Preference test}

A preliminary trial was conducted in April to test for the growing rabbits' preference for potential cage enrichment materials. The choice of materials was based on availability and cost, thus pieces of wood $(0.15 \times 0.03 \times 0.03 \mathrm{~m})$ (Eucalyptus sp, Pinus sp), bamboo (Dendrocalamus giganteus), and PVC pipe (Tigre, Brazil) were used. The last two were $0.15 \mathrm{~m}$ long and $0.03 \mathrm{~m}$ in diameter. Fortyeight weaned male and female rabbits were allocated six per cage, in a completely randomized design with four treatments (enrichment materials). In each cage at least two rabbits were from the same sex. Two different enrichment pieces were suspended $0.43 \mathrm{~m}$ apart with wire from the cage ceiling and their height was adjusted weekly according to the animals' size, from 0.20 to $0.30 \mathrm{~m}$ above the cage floor (Fig. 1). The number of interactions with the enrichment materials (Table 1 ) was counted over four one-hour periods 


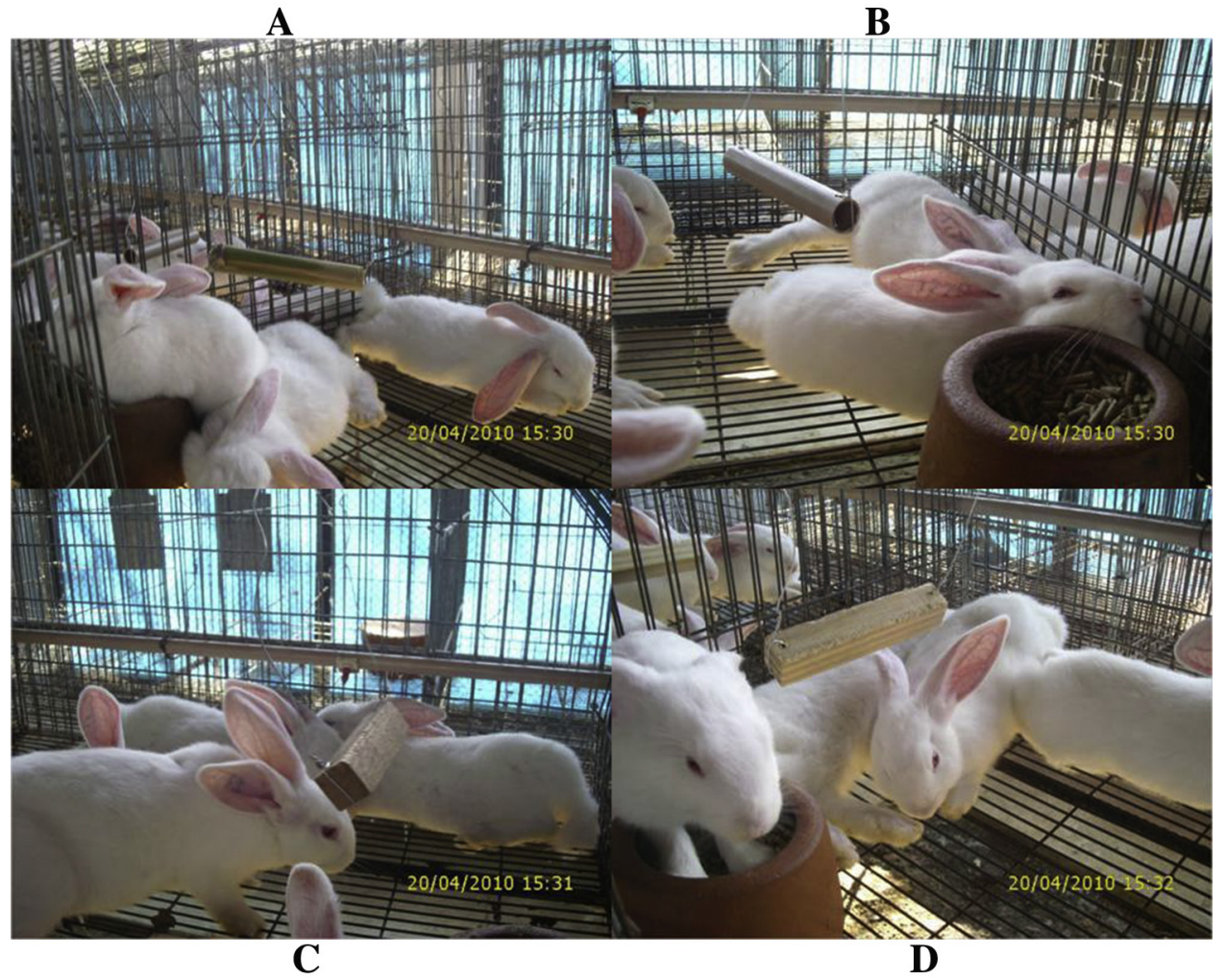

Fig. 1. Cages with enrichments made of (A) bamboo (Dendrocalamus giganteus), (B) PVC pipe, (C) Eucalyptus sp, and (D) Pinus sp.

Table 1

Description of behavior patterns (based on Morisse and Maurice, 1997) and recording method.

\begin{tabular}{|c|c|c|}
\hline Activity & Description & $\begin{array}{l}\text { Recording } \\
\text { method }\end{array}$ \\
\hline Resting & Sitting, lying or sleeping & Scan sampling \\
\hline Self-grooming & $\begin{array}{l}\text { Licking, scratching, or nibbling of the } \\
\text { body }\end{array}$ & Scan sampling \\
\hline Feeding & Eating or drinking & Scan sampling \\
\hline Social interaction & $\begin{array}{l}\text { Making contact, rubbing, licking, and } \\
\text { sniffing others }\end{array}$ & $\begin{array}{l}\text { All occurrence } \\
\text { sampling }\end{array}$ \\
\hline $\begin{array}{l}\text { Investigatory } \\
\text { behavior }\end{array}$ & $\begin{array}{l}\text { Voluntary movements, rubbing, } \\
\text { licking, gnawing, or chin marking the } \\
\text { cage and its equipment, including the } \\
\text { enrichment }\end{array}$ & $\begin{array}{l}\text { All occurrence } \\
\text { sampling }\end{array}$ \\
\hline Caecotrophy & $\begin{array}{l}\text { The body is twisted around with the } \\
\text { mouth towards the anus }\end{array}$ & $\begin{array}{l}\text { All occurrence } \\
\text { sampling }\end{array}$ \\
\hline $\begin{array}{l}\text { Interaction with } \\
\text { enrichment }\end{array}$ & $\begin{array}{l}\text { Sniffing, licking, gnawing, and pushing } \\
\text { either the stick or the wire }\end{array}$ & $\begin{array}{l}\text { All occurrence } \\
\text { sampling }\end{array}$ \\
\hline $\begin{array}{l}\text { Stereotyped } \\
\text { behavior }\end{array}$ & $\begin{array}{l}\text { Licking or gnawing cage bars and } \\
\text { scratching cage floor insistently }\end{array}$ & $\begin{array}{l}\text { All occurrence } \\
\text { sampling }\end{array}$ \\
\hline $\begin{array}{l}\text { Aggressive } \\
\text { behavior }\end{array}$ & Fighting with or biting another rabbit & $\begin{array}{l}\text { All occurrence } \\
\text { sampling }\end{array}$ \\
\hline
\end{tabular}

(7:00-8:00 am, 1:00-2:00 pm, 7:00-8:00 pm, and 1:00-2:00 am) once a week from weeks 7-11 and totaled for each enrichment material. Six trained observers were involved in the observations of animal interactions with the enrichment materials. They observed four cages at a time standing approximately $0.90 \mathrm{~m}$ from the cages, and recorded "an interaction with enrichment" every time a rabbit sniffed, licked, gnawed or pushed an enrichment item (stick, pipe or wire). No animal deaths were recorded during the preference test. The results were analyzed using goodness-of-fit Chi-square tests.

\subsection{Effect of enrichment and composition of the social group on behavior and welfare of growing rabbits}

This experiment involved 72 male and 72 female rabbits in two batches (July/August and September/October) of 36 males and 36 females. It was initiated at 42 days and finished at 77 days of age. The animals were assigned to a completely randomized design, in a $2 \times 3$ factorial arrangement (with or without cage enrichment and three compositions of social group: males, females, or mixed gender) with repeated measures (12 two-hour periods/day on three days) and four replicates (two replicates per batch) totaling 864 observations. Stocking density was $800 \mathrm{~cm}^{2}$ with six rabbits per cage $(0.60 \times 0.80 \times 0.45 \mathrm{~m})$. Mixed gender cages had equal numbers of males and females. In enriched cages two eucalyptus sticks were hung $50 \mathrm{~cm}$ apart from the cage ceiling, $20-30 \mathrm{~cm}$ from the floor.

Six surveillance cameras (Mini Câmera Ccd Color Sharp 1/4 420L, 0.1 Lux, Day-Night - 12v 150 ma, Sharp Corporation, São Paulo, Brazil) were used for video recording 12 cages simultaneously during $24 \mathrm{~h}$, when the rabbits were 49,70 and 77 days old. The cameras were mounted on metal supports positioned $0.60 \mathrm{~m}$ above the cages and $1.20 \mathrm{~m}$ from the cage ceilings. The behavioral activities were registered as described in Table 1, based on Morisse and Maurice (1997): "feeding”, "resting”, "self-grooming”, "interacting socially", "investigatory behaviors", "stereotyped”, and "caecotrophy". Cages were scanned once every 20 min for feeding, resting, and self-grooming behaviors. The results of the scans were expressed as the proportion of animals performing a certain behavior per cage per two-hour period each day. The other behaviors (interacting socially, investigatory, and caecotrophy) were recorded every time they occurred (all occurrence sampling) for five minutes every $20 \mathrm{~min}$, that is, for a total of $30 \mathrm{~min}$ every two-hour period on each of the three days. "Interaction with the 
enrichment" and "stereotyped" and "aggressive" behaviors were also recorded using all occurrence sampling (Table 1). The numbers of occurrences per two-hour period per day were totaled on a cage basis and used in the analyses.

Ten rabbits (6.9\%) died from diarrhea, among which eight were in the first batch (11.1\%) and two in the second (2.8\%).

\subsection{Effect of enrichment and composition of the social group on growth performance, skin wounds, and brain weight}

Rabbits were weighed at 42 and 77 days of age and average daily gain was calculated on a cage basis. Weekly feed consumption was estimated by weighing the amount of feed offered and the orts. Average feed consumption and feed conversion from 42 to 77 days of age were also calculated on a cage basis. At 77 days, the animals were fasted for $12 \mathrm{~h}$, and then transported to the Experimental Slaughter House, where the number of individuals that had skin wounds on the ears and other body parts was recorded before slaughter. The rabbits were stunned by eletronarcosis (220 V, $0.7 \mathrm{~A}$ ) and exsanguinated from the jugular vein (Close et al., 1997). The frontal bone was then cut using stainless steel scissors (Tramontina S.A., Farroupilha, Brazil) to collect the brain, which was weighed on an analytical scale (Bel Photonics do Brasil Ltda., Piracicaba, Brazil). Cage averages were used in the analyses.

\subsection{Statistical analyses}

Behaviors were submitted to three-way (enrichment, social group, and day) split-plot (between/within) ANOVA implemented in the MIXED procedure of SAS (2003). The models included the fixed effects of batch, hour, enrichment, social group, age, and the two-way interactions between the last three effects. Two random errors were defined (Kaps and Lamberson 2009): (1) the variance between cages within treatments and (2) the variance between measurements [hours(days)] within cages. The first random error was used to test the effects of enrichment, social group, and the enrichment $\times$ social group interaction. The second random error was used to test age effect and the effects of the two-way interactions involving age. An autoregressive covariance structure [AR(1)] was employed. Appropriate $t$-tests were computed to make pairwise comparisons of social group least-square means. Pre-planned contrasts were employed to compare means when interaction effects were present. The model used for the analyses of the number of interactions with the enrichment was simpler because only a sub-set of data (enriched cages) was used. Thus, the effects of enrichment and its two-way interactions had to be excluded. The actual number of rabbits in each cage at the time of observation was used as a covariate in the analyses of behavioral traits.

Low frequency of occurrence was recorded for stereotyped and aggressive behaviors, thus the two-hour period records were zero inflated, precluding analyses using complex models. Therefore, for these two behavioral traits and for skin wound count, the total counts were totaled for each enrichment $\times$ social group combination over time and replicates. Fisher's exact test was used to test for independence between enrichment and social group effects. Because these effects were found to be independent for all three variables $(P>0.05)$, specific goodness-of-fit chi-square tests were run for enrichment and social group followed by a Bonferroni correction.

Performance traits and brain weight were submitted to twoway ANOVA using the GLM procedure of SAS (2003). The models included the fixed effects of batch, enrichment, social group, and the enrichment $\times$ social group interaction plus the random error. Body weight on day 77 was used as a covariate in the analysis of brain weight.
Table 2

Total counts and percentage of interactions of rabbits with cage enrichment made of different materials.

\begin{tabular}{lll}
\hline Material & Number of interactions & $(\%)$ \\
\hline Eucalyptus $s p$ & $130^{\mathrm{d}}$ & 29.7 \\
Pinus $s p$ & $115^{\mathrm{d}}$ & 26.3 \\
Dendrocalamus giganteus & $123^{\mathrm{d}}$ & 28.8 \\
PVC pipe & $66^{\mathrm{c}}$ & 15.1
\end{tabular}

Overall $\chi_{(3)}^{2}=23.2(\mathrm{P}<0.0001)$.

c,d Differ according to Bonferroni correction at $\mathrm{P}<0.01$ after pairwise chi-square goodness of fit tests.

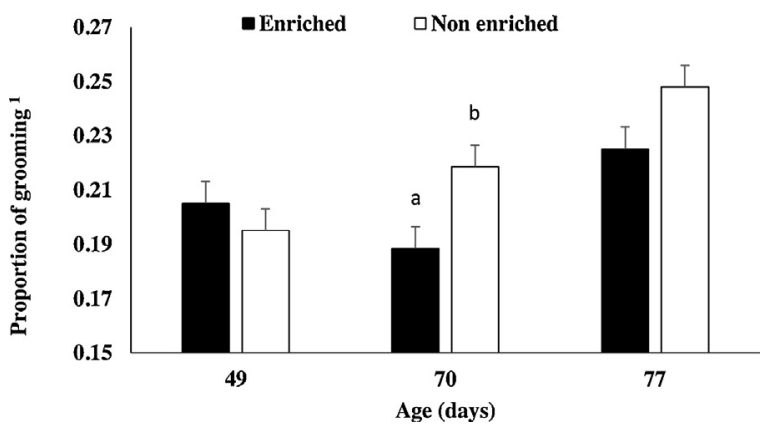

Fig. 2. Enrichment $x$ age interaction effect $\left(F_{(2,40)}=3.68, P=0.034\right)$ on self-grooming behavior ${ }^{1}$.

a,b differ $(\mathrm{P}<0.05)$ according to pre-planned contrasts.

${ }^{1}$ The proportion of rabbits performing comfort and maintenance behaviors (resting, self-grooming and feeding) was averaged for a total of 30 min every two-hour period at 49,70 , and 77 days of age, on a cage basis, by scan sampling.

\section{Results}

\subsection{Preference test}

Tests were conducted to assess the preference of growing rabbits for different materials used in the enrichment of the cage environment. During these tests, animals interacted less $(\mathrm{P}<0.01)$ with the PVC pipe in comparison with enrichments made of wooden materials. However, no differences among Eucalyptus, Pinus, and Dendrocalamus were detected (Table 2). Thus, because of availability we used Eucalyptus sticks for environmental enrichment.

\subsection{Behavior}

No enrichment $\times$ social group composition interaction effects on behavioral traits, either recorded by scan sampling or by alloccurrence sampling were detected $(\mathrm{P}>0.05)$. Therefore, these two effects were considered separately (Tables 3 and 4 ).

\subsubsection{Enrichment effects on behavior}

The presence of wooden sticks in the cages decreased selfgrooming, but resting and feeding were unaffected (Table 3 ). There was an enrichment $x$ age interaction effect $\left(F_{(2,40)}=3.68, P=0.034\right)$ for self-grooming. On day 49 , no difference in self-grooming was found between enriched and non-enriched cages, but on day 70 rabbits in non-enriched cages showed higher frequency of selfgrooming (Fig. 2). On day 77, the same trend was still present $(\mathrm{P}=0.05)$.

Enrichment also decreased the number of social interactions among rabbits, but the incidence of investigatory behavior and caecotrophy was unchanged (Table 4). Stereotyped behaviors were unaffected, whereas aggressive behaviors were increased by enrichment (Table 5). 
Table 3

Proportions of comfort and maintenance behaviors recorded by scan sampling, according to enrichment and social group.

\begin{tabular}{|c|c|c|c|c|c|c|c|}
\hline \multirow[t]{2}{*}{ Behavior $^{\mathrm{a}}$} & \multicolumn{2}{|l|}{ Enrichment } & \multirow[t]{2}{*}{ Statistics } & \multicolumn{3}{|l|}{ Social group } & \multirow[t]{2}{*}{ Statistics } \\
\hline & Yes & No & & Males & Females & Mixed & \\
\hline Resting & $0.6726 \pm 0.0063$ & $0.6564 \pm 0.0063$ & $\begin{array}{l}F_{(1,17)}=3.09 \\
P=0.097\end{array}$ & $0.6709 \pm 0.0076$ & $0.6599 \pm 0.0075$ & $0.6627 \pm 0.0076$ & $\begin{array}{l}F_{(2,17)}=0.58 \\
P=0.573\end{array}$ \\
\hline Self-grooming & $0.2061 \pm 0.0047$ & $0.2205 \pm 0.0047$ & $\begin{array}{l}F_{(1,17)}=4.50 \\
P=0.049\end{array}$ & $0.2060 \pm 0.0056$ & $0.2133 \pm 0.0056$ & $0.2207 \pm 0.0056$ & $\begin{array}{l}F_{(2,17)}=1.70 \\
P=0.213\end{array}$ \\
\hline Feeding & $0.1213 \pm 0.0039$ & $0.1232 \pm 0.0039$ & $\begin{array}{l}F_{(1,17)}=0.11 \\
P=0.747\end{array}$ & $0.1232 \pm 0.0047$ & $0.1267 \pm 0.0046$ & $0.1167 \pm 0.0047$ & $\begin{array}{l}F_{(2,17)}=1.19 \\
P=0.327\end{array}$ \\
\hline
\end{tabular}

a The proportion of rabbits performing each one of these activities was determined once every twenty minutes and averaged for two-hour periods at 49 , 70 , and 77 days of age, on a cage basis, by scan sampling.

Table 4

Frequency of behaviors according to enrichment and social group.

\begin{tabular}{|c|c|c|c|c|c|c|c|}
\hline \multirow[t]{2}{*}{ Behavior $^{\mathrm{a}}$} & \multicolumn{2}{|l|}{ Enrichment } & \multirow[t]{2}{*}{ Statistics } & \multicolumn{3}{|l|}{ Social group } & \multirow[t]{2}{*}{ Statistics } \\
\hline & Yes & No & & Males & Females & Mixed & \\
\hline $\begin{array}{l}\text { Social } \\
\text { interaction }\end{array}$ & $9.40 \pm 0.15$ & $10.03 \pm 0.15$ & $\begin{array}{l}F_{(1,17)}=8.02 \\
P=0.012\end{array}$ & $9.46 \pm 0.18^{c}$ & $9.42 \pm 0.18^{c}$ & $10.27 \pm 0.18^{d}$ & $\begin{array}{l}F_{(2,17)}=6.74 \\
P=0.007\end{array}$ \\
\hline Investigatory & $6.25 \pm 0.18$ & $6.14 \pm 0.18$ & $\begin{array}{l}F_{(1,17)}=0.16 \\
P=0.693\end{array}$ & $6.27 \pm 0.22$ & $5.89 \pm 0.21$ & $6.42 \pm 0.22$ & $\begin{array}{l}F_{(2,17)}=1.60 \\
P=0.231\end{array}$ \\
\hline Caecotrophy & $1.223 \pm 0.065$ & $1.299 \pm 0.065$ & $\begin{array}{l}F_{(1,17)}=0.63 \\
P=0.437\end{array}$ & $1.277 \pm 0.078$ & $1.136 \pm 0.077$ & $1.369 \pm 0.078$ & $\begin{array}{l}F_{(2,17)}=2.29 \\
P=0.132\end{array}$ \\
\hline $\begin{array}{l}\text { Inter. } \\
\mathrm{w} / \text { enrichment }\end{array}$ & - & - & - & $4.02 \pm 0.26$ & $3.92 \pm 0.26$ & $3.84 \pm 0.27$ & $\begin{array}{l}\mathrm{F}_{(2,17)}=0.12 \\
\mathrm{P}=0.892\end{array}$ \\
\hline
\end{tabular}

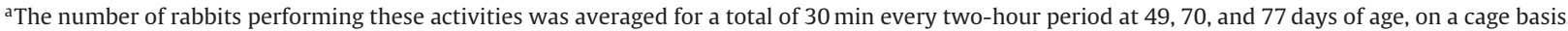

$\mathrm{b}, \mathrm{c}$ differ at $\mathrm{P}<0.01$, according to pairwise $t$-tests of means.

Table 5

Frequency of behaviors and number of individuals with skin wounds according to enrichment and social group.

\begin{tabular}{|c|c|c|c|c|c|c|c|}
\hline \multirow[t]{2}{*}{ Trait } & \multicolumn{2}{|c|}{ Enrichment } & \multirow[t]{2}{*}{ Statistics } & \multicolumn{3}{|c|}{ Social group } & \multirow[t]{2}{*}{ Statistics } \\
\hline & Yes & No & & Males & Females & Mixed & \\
\hline \multicolumn{8}{|l|}{ Behaviors $^{\mathrm{a}}$} \\
\hline Stereotyped & 7 & 15 & $\begin{array}{l}\chi_{(1)}^{2}=2.91 \\
P=0.088\end{array}$ & $9^{d}$ & $12^{\mathrm{d}}$ & $1^{\mathrm{c}}$ & $\begin{array}{l}\chi^{2}(2)=8.82 \\
P=0.012\end{array}$ \\
\hline Aggressive & 60 & 34 & $\begin{array}{l}\chi^{2}(1)=7.19 \\
P=0.007\end{array}$ & $47^{\mathrm{d}}$ & $15^{c}$ & $32^{d}$ & $\begin{array}{l}\chi^{2}(2)=16.36 \\
P<0.001\end{array}$ \\
\hline Skin wounds ${ }^{b}$ & 11 & 28 & $\begin{array}{l}\chi_{(1)}^{2}=7.41 \\
P=0.006\end{array}$ & $14^{\mathrm{c}, \mathrm{d}}$ & $6^{c}$ & $19^{d}$ & $\begin{array}{l}\chi^{2}(2)=6.62 \\
P=0.037\end{array}$ \\
\hline
\end{tabular}

a The number of rabbits performing these activities for a total of 30 min every two-hour period at 49,70 , and 77 days of age was totaled for each treatment subclass.

${ }^{b}$ The number of individuals with skin wounds recorded at 77 days of age.

${ }^{\mathrm{c}, \mathrm{d}}$ Differ at $\mathrm{P}<0.05$ by pairwise chi-square tests followed by a Bonferroni correction.

\subsubsection{Social group effects on behavior}

No effects of social group composition were detected on the proportions of maintenance (feeding) and comfort (resting and selfgrooming) behaviors (Table 3 ). However, the incidence of social interactions was higher in mixed-gender than in same-sex groups (Table 4). The manifestation of investigatory behavior, caecotrophy, and interaction with enrichment materials was unaffected by the composition of the social group (Table 4).

Mixed-gender groups showed the lowest incidence of stereotyped behaviors, whereas male and mixed-gender groups presented higher incidences of aggressive behaviors than female groups (Table 5).

\subsubsection{Age effects on behavior}

The proportion of feeding (relative to all comfort and maintenance behaviors) decreased with age $\left(\mathrm{F}_{(2,40)}=30.64, \mathrm{P}<0.001\right)$, from $0.1541 \pm 0.0049$ at 49 days of age to $0.1041 \pm 0.0046$ at 77 days of age, whereas the proportion of self-grooming increased $\left(\mathrm{F}_{(2,40)}=12.79, \mathrm{P}<0.001\right)$ from $0.2001 \pm 0.0058$ at 49 days of age to $0.2365 \pm 0.0056$ at 77 days of age. The relative proportion of resting behavior also changed with age $\left(\mathrm{F}_{(2,40)}=9.09, \mathrm{P}<0.001\right)$ : it increased from $0.6455 \pm 0.0079$ at 49 days of age to $0.6899 \pm 0.0075$ at 70 days of age, but decreased to $0.6581 \pm 0.0075$ at 77 days of age. There was no age effect on the occurrence of social interactions $\left(\mathrm{F}_{(2,40)}=2.29, \mathrm{P}=0.114\right)$, investigatory behaviors $\left(\mathrm{F}_{(2,40)}=1.03\right.$, $P=0.366)$, or interaction with enrichment materials $\left(F_{(2,18)}=2,33\right.$, $\mathrm{P}=0.126)$, but the frequency of caecotrophy decreased with age $\left(\mathrm{F}_{(2,40)}=29.49, \mathrm{P}<0.001\right)$ from $1.774 \pm 0.082$ at 49 days of age to $0.894 \pm 0.078$ at 77 days of age.

\subsection{Growth performance, brain weight, and skin wounds}

Growth performance from 42 to 77 days was unaffected by enrichment or by the composition of the social group. The initial (42 days) and final mean weights ( 77 days), average daily gains, feed consumption, and feed conversion were, respectively: $983 \pm 24 \mathrm{~g}, 2274 \pm 21 \mathrm{~g}, 36.89 \pm 0.42 \mathrm{~g} /$ day, $108.2 \pm 2.4 \mathrm{~g} /$ day, and $2.933 \pm 0.080$

An enrichment $\times$ social group interaction effect $\left(F_{(2,16)}=3.88\right.$, $\mathrm{P}=0.042$ ) was found on brain weight on day 77 . Males in enriched cages had heavier brains than those in non-enriched cages (8.52 \pm 0.21 vs. $7.86 \pm 0.22 \mathrm{~g}$, respectively), whereas no differences 


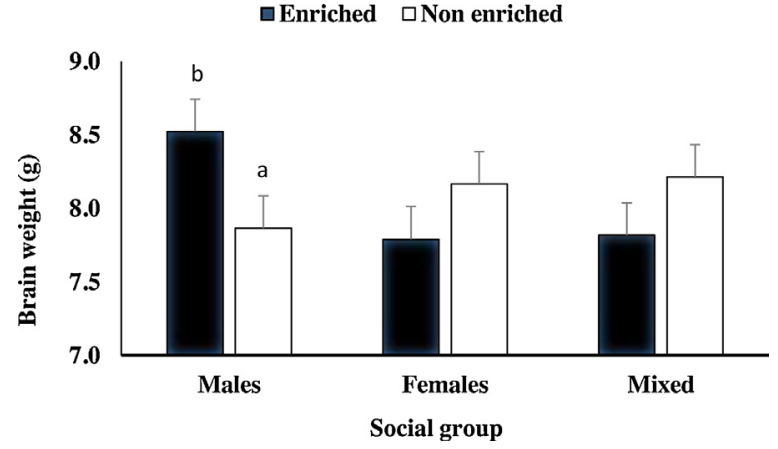

Fig. 3. Enrichment $\times$ social group interaction effect $\left(F_{(2,16)}=3.88, P=0.042\right)$ on brain weight at 77 days of age.

$\mathrm{a}, \mathrm{b}$ differ $(\mathrm{P}<0.05)$ according to pre-planned contrasts.

in brain weights between enriched and non-enriched cages were found for females or mixed genders (Fig. 3).

The number of animals having skin wounds at slaughter, on day 77, was lower in enriched than in non-enriched cages (Table 5). On the other hand, the number of animals showing skin wounds at slaughter was higher in mixed-gender groups than in female groups, while male groups were at an intermediate level.

\section{Discussion}

In the preliminary test to assess preference for enrichment materials, animals interacted less with the PVC pipe in comparison with the enrichments made of Eucalyptus, Pinus or bamboo. Because there were no differences among Eucalyptus, Pinus, and bamboo and given the greater local availability, we chose to employ Eucalyptus sticks for environmental enrichment in the subsequent experiment.

The preference for enrichment materials was determined from the number of interactions the animals had with each material. A previous work defined rabbit preference based on the ingestion volume of gnawing sticks from nine different species of trees (Princz et al., 2007). In that study, sticks from five species were partially ingested (Little-leaf linden, White willow, White buckeye, Black poplar, and White locust), whereas the others were not ingested.

No enrichment $\times$ social group interaction effect was detected on any behavioral traits, but there were main effects of enrichment and social group on those traits. Enrichment of cages with Eucalyptus sticks decreased self-grooming in older animals and the number of social interactions with conspecifics, but it also increased the number of times that rabbits demonstrated aggressive behavior. However, the number of skin wounds at 77 days of age was lower in enriched cages, indicating that the number of skin wounds is independent of the incidence of aggressive behavior in the postweaning period. The correlation between these two variables was very low $(r=-0.048, P=0.928)$. It seems paradoxical that increased aggressive behavior was accompanied by a decrease in the number of skin wounds. Increased aggression could indicate that some sort of dispute for the enrichment was occurring among the rabbits.

These findings suggest that the time spent interacting with the enrichment reduces the time dedicated to self-grooming and social contacts. Increased self-grooming may reflect stress and lack of stimuli from the environment in rabbits kept in conventional cage systems (Hansen and Berthelsen, 2000). Hence, the presence of the sticks in the cage may have prevented increased self-grooming as age advanced, thus improving welfare. Decreased social contact in cages enriched with a "u" shaped wooden structure was also reported (Buijs et al., 2011). Social contact among rabbits is generally viewed as positive, but decreased social contact among animals housed in groups could lead to improved welfare in some circum- stances, for example if unwanted social contact is avoided (Buijs et al., 2011).

An increase in aggressive behavior was associated with environmental enrichment. This was not previously reported in rabbits. In fact, in Pannon White rabbits, the use of white locust sticks in cages (two rabbits) or pens (13 rabbits) had the opposite effect, reducing aggressive behavior (Princz et al., 2007, 2008) suggesting that a strain difference regarding aggressive behavior may exist. In several mouse strains, environmental enrichment induced aggressiveness. Adolescent and young adult NMRI male mice exposed to environmental enrichment during rearing showed increased agonistic behavior in comparison to controls kept in a non-enriched environment (Mesa-Gresa et al., 2013). In CD-1 mice, environmental enrichment was found to increase aggressive behaviors (McQuaid et al., 2012). In male mice, increased aggression is associated with territoriality and a similar behavior may have occurred in male rabbits in the present study.

In wild rabbits, social rank orders are established and maintained by intensive fights (Von Holst et al., 2002). In captive rabbits, the establishment of hierarchy occurs at approximately 10 weeks of age in mixed-gender rabbit groups, and the highest incidence of wounds was observed in cages with steepest hierarchy (Vervaecke et al., 2010). In a linear hierarchy, steepness measures the degree to which individuals differ from each other in winning dominance encounters (De Vries et al., 2006). A steep hierarchy denotes an authoritarian dominance hierarchy with large rank differences, whereas a more egalitarian dominance hierarchy presents small rank differences. We speculate that the enrichment may have favored a more stable, egalitarian hierarchical dominance, with smaller rank distances among animals. In the absence of a suitable gnawing substrate, rabbits in unenriched cages may have a tendency to bite their conspecifics (Buijs et al., 2011). These findings agree with those from a previous study in which the number of ear injuries was lower in rabbits housed in pens provided with gnawing sticks (Princz et al., 2008).

The composition of the social group did not influence the proportions of maintenance and comfort behaviors. It did, however, affect the incidence of social interactions as well as of aggressive and stereotypic behaviors. These findings have not been previously reported. Mixed-gender groups had a lower incidence of stereotypes and a higher incidence of social interactions than same-sex groups. This may reflect a greater interest in individuals from the opposite sex, especially as rabbits approach puberty. Lower incidences of stereotypes and higher incidences of social interactions are indications of improved welfare, but these changes were associated with an increase in the number of skin wounds, compared to female-only groups. Szendrö et al. (2012) did not report any effects of sex-composition of the groups on the behavior of growing rabbits, but at 11 weeks of age, the number of skin injuries was higher in male groups. More frequent aggressive behavior in male groups is expected, since fighting among young and adult male rabbits is well documented (Verga et al., 2007).

As age advanced, eating and drinking as well as caecotrophy decreased, whereas self-grooming increased. Six-week-old rabbits fed a pelleted diet spent over three hours daily feeding, but this period was reduced to less than two hours subsequently (Gidenne et al., 2010). Longer periods and a biphasic pattern of caecotrophy were seen in newly-weaned, compared to adult rabbits (Bellier et al., 1995). In the present study, resting frequency increased from day 49 to day 70, but decreased thereafter. This pattern suggests that the time spent eating or resting on day 49 was gradually exchanged for time spent on self-grooming. Restlessness on day 77 could be partly attributed to social stress caused by hierarchy establishment, which takes place at approximately 70 days of age (Vervaecke et al., 2010). With Pannon White rabbits in cages or pens as age increased, rabbits spent more time resting and less time eat- 
ing, drinking, and self-grooming (Princz et al., 2008). Age had a more pronounced effect on maintenance and comfort behaviors of growing rabbits than environmental enrichment and the composition of the social group.

An increase in brain weight was seen in males from samesex groups in enriched cages, but no differences were found in female and mixed groups. This is a novel finding in rabbits and deserves further investigation, since increased brain weight has been reported in rats (Diamond et al., 1964) and mice (Van Praag et al., 2000) provided with extra environmental stimulus. Both the visual and sensorial areas of their brains were enlarged, leading us to speculate that environmental enrichment also promoted the development of specific brain regions in rabbits. Examples of structural and functional changes in the brain resulting from environmental enrichment in rodents and other animal species are increased volume (Scholz et al., 2015) increased cortical thickness and enhanced dendritic ramification (Beaulieu and Colonnier, 1987; Rosenzweig and Bennet, 1996), increased neurogenesis in the hippocampus (Kempermann et al., 1997), and improved memory in learning tasks (Van Praag et al., 2000). The reason why we did not find the same effect of enrichment on brain weight in female or mixed-gender groups is not clear. It may be that social interactions among males in only-male groups (including conflicts and rank formation) became more complex as they approached sexual maturity, influencing brain development.

\section{Conclusions}

A preliminary trial assessed rabbit preference for cage enrichment materials. Based on this trial, we used eucalyptus for environmental enrichment in the subsequent study.

In enriched environments, social interactions and self-grooming were reduced, but aggressive behaviors increased, suggesting that environmental enrichment may have altered rank formation. Despite this, the number of animals with skin wounds was lower in enriched cages, indicating improved welfare. The incidence of skin wounds at the end of the fattening period was independent of the frequency of aggressive behavior in the post-weaning period.

Based on the decreased incidence of stereotyped behaviors and increased social interactions, we recommend that mixed-gender groups of rabbits be maintained in collective cages from weaning to 11 weeks of age. However, if the incidence of skin wounds is considered, all-female groups are the most desirable. For males, the age at which fighting becomes more intense should be determined for each strain, breed, or cross, and from then on, individual cages should be preferred.

This is the first time that an increase in aggressive behavior is reported as result of environmental enrichment in rabbits. In addition, it is the first report on how the composition of the social group influences the interactions among rabbits kept in the same cage and the incidence of stereotyped behavior. Our study is also the first to report how environmental enrichment affects brain development in rabbits, although further investigations are needed.

\section{Acknowledgements}

TFM Bozicovich received a Masters' research assistantship from the Fundação de Amparo à Pesquisa do Estado de São Paulo (FAPESP), Brazil (protocol number: 2009/12068-3). ASAMT Moura is the recipient of a productivity assistantship from the Conselho Nacional de Desenvolvimento Científico e Tecnológico (CNPq), Brazil.

\section{References}

Bõsze, Zs., Houdebine, L.M., 2006. Application of rabbits in biomedical research: a review. World Rabbit Sci. 14, 1-14
Beaulieu, C., Colonnier, M., 1987. Effect of the richness of the environment on the cat visual cortex. J. Comp. Neurol. 266, 478-494.

Bellier, R., Gidenne, T., Vernay, M., Colin, M., 1995. In vivo study of circadian variation of the cecal fermentation pattern in postweaned and adult rabbits. J. Anim. Sci. 73, 128-135.

Bianospino, E., Wechsler, F.S., Fernandes, S., Roça, R.O., Moura, A.S.A.M.T., 2006. Growth, carcass and meat quality traits of straightbred and crossbred Botucatu rabbits. World Rabbit Sci. 14, 237-246.

Buijs, S., Keeling, L.J., Rettenbacher, S., Tuyttens, F.A.M., 2011. Behaviour and use of space in fattening rabbits as influenced by cage size and enrichment. Appl. Anim. Behav. Sci. 134, 229-238.

Chu, L., Garner, J.P., Mench, J.A., 2004. A behavioral comparison of New Zealand White rabbits (Oryctolagus cuniculus) housed individually or in pairs in conventional laboratory cages. Appl. Anim. Behav. Sci. 85, 121-139.

Close, B., Banister, K., Baumans, V., Bernoth, E., Bromage, N., Bunyan, J., Erhardt, W. Flecknell, P., Gregory, M., Hackbarth, H., Morton, D., Warwick, C., 1997. Recommendations for euthanasia of experimental animals: part 2. DGXT of the European Commission. Lab. Anim. 31, 1-32.

De Vries, H., Stevens, J.M.G., Vervaecke, H., 2006. Measuring and testing the steepness of dominance hierarchies. Anim. Behav. 71, 585-592.

Diamond, M.C., Krech, D., Rosenweig, M.R., 1964. The effects of an enriched environment on the histology of the rat cerebral cortex. J. Comp. Neurol. 123, $111-119$.

Directive 2010/63/EU of the European Parliament and of the Council on the protection of animals used for scientific purposes. Official J. Europ. Union, 53:33-79. http://eur-lex.europa.eu/legal-content/EN/AUTO/?uri=uriserv:OJ.L_. 2010.276.01.0033.01.ENG\&toc=OJ:L: 2010:276:TOC.

EFSA (European Food and Safety Authority), 2005. The impact of the current housing and husbandry systems on the health and welfare of farmed domestic rabbits. EFSA J. 267, 1-31.

Gidenne, T., Lebas, F., Fortun-Lamothe, L., 2010. Feeding behavior of rabbits. In: De Blas, C., Wiseman, J. (Eds.), Nutrition of the Rabbit. CABI Publishing, Wallingford, UK, pp. 233-252.

Grosse-Hovest, L., Müller, S., Minoia, R., Wolf, E., Zakhartchenko, V., Wenigerkind, H., Lassnig, C., Besenfelder, U., Müller, M., Lytton, S.D., Jung, G., Brem, G., 2004. Cloned transgenic farm animals produce a bispecific antibody for $\mathrm{T}$ cell-mediated tumor cell killing. PNAS 101, 6858-6863.

Gunn, D., Morton, D.B., 1995. Inventory of the behavior of New Zealand White rabbits in laboratory cages. Appl. Anim. Behav. Sci. 45, 277-292.

Gwon, A., 2008. The rabbit in cataract/IOL surgery. In: Tsonis, P.A. (Ed.), Animal Models in Eye Research. Academic Press San Diego, USA, pp. $184-204$.

Hanly, W.C., Artwohl, J.E., Bennett, B.T., 1995. Review of polyclonal antibody production procedures in mammals and poultry. ILAR J. 37, 93-118.

Hansen, L.T., Berthelsen, H., 2000. The effect of environmental enrichment on the behavior of caged rabbits (Oryctolagus cuniculus). Appl. Anim. Behav. Sci. 68, 163-178.

Jordan, D., Luzi, F., Verga, M., Stuhec, I., 2006. Environmental enrichment in growing rabbits. In: Maertens, Coudert (Eds.), Recent Advances in Rabbit Sciences. ILVO, COST, Melle, Belgium, pp. 113-119.

Kang, S.J., Grossniklaus, H.E., 2011. Rabbit model of retinoblastoma. J. Biomed. Biotech. 2011, 5, http://dx.doi.org/10.1155/2011/394730 (Article ID 394730).

Kaps, M., Lamberson, W.R., 2009. Repeated measures. In: Kaps, M., Lamberson, W.R. (Eds.), Biostatistics for Animal Science., 2nd ed. CABI Publishing, Wallingford, pp. 405-443

Kempermann, G., Kuhn, H.G., Gage, F.H., 1997. More hippocampal neurons in adult mice living in an enriched environment. Nature 386, 493-495.

Korstanje, R., 2000. Development of a genetic and comparative map of the rabbit In: A Tool for QTL Mapping. Utrecht University.

Mapara, M., Thomas, B.S., Bhat, K.M., 2012. Rabbit as an animal model for experimental research. Dental Res. J. 9, 111-118.

McQuaid, R.J., Audet, M., Anisman, H., 2012. Environmental enrichment in male CD-1 mice promotes aggressive behaviors and elevated corticosterone and brain norepinephrine activity in response to a mild stressor. Stress 15 354-360.

Mesa-Gresa, P., Pérez-Martinez, A., Redolat, R., 2013. Environmental enrichment improves novel object recognition and enhances agonistic behavior in male mice. Aggressive Behav. 39, 269-279.

Morisse, J.P., Maurice, R., 1997. Influence of stocking density or group size on behavior of fattening rabbits kept under intensive conditions. Appl. Anim. Behav. Sci. 54, 351-357.

Newberry, R.C., 1995. Environmental enrichment: increasing the biological relevance of captive environments. Appl. Anim. Behav. Sci. 44, 229-243.

Olsson, I.A.S., Dahlborn, K., 2002. Improving housing conditions for laboratory mice: a review of 'environmental enrichment'. Lab. Anim. 36, 243-270.

Princz, Z., Orova, Z., Nagy, I., Jordan, D., Stuhec, I., Luzi, F., Verga, M., Szendrö, Zs., 2007. Application of gnawing sticks in rabbit housing. World Rabbit Sci. 15, 29-36.

Princz, Z., Dalle Zotte, A., Radnai, I., Biró-Németh, E., Matics, Z., Gerencsér, Z., Nagy, I., Szendrö, Z., 2008. Behaviour of growing rabbits under various housing conditions. Appl. Anim. Behav. Sci. 111, 342-356.

Rosenzweig, M.R., Bennet, E.L., 1996. Psychobiology of plasticity: effects of training and experience on brain and behavior. Behav. Brain Res. 78, 57-65

SAS/STAT. 2003. User's Guide (Release 9.1.3 Service Pack 2). SAS Inst. Inc. Cary. 
Scholz, J., Allemang-Grand, R., Dazai, J., Lerch, J., 2015. Environmental enrichment is associated with rapid volumetric brain change in adult mice. Neurolmage 109, 190-198.

Siloto, E.V., Moura, A.S.A.M.T., Zeferino, C.P., Fernandes, S., Sartori, J.R., Siqueira, E.R., 2008. Temperatura e enriquecimento ambiental sobre o bem-estar de coelhos em crescimento. Ciênc. Rural 39, 528-533.

Stübinger, S., Dard, M., 2013. The rabbit as experimental model for research in implant dentistry and related tissue regeneration. J. Invest. Surg. 26, 266-282.

Szendrö, Z., Dalle Zotte, A., 2011. Effect of housing conditions on production and behavior of growing meat rabbits. A Eev. Livest. Sci. 137, 296-303.

Szendrö, Z., Gerencsér, Z., Odermatt, M., Dalle Zotte, A., Zendri, F., Radnai, I., Nagy, I., Matics, Z., 2012. Production and Behavior of Growing Rabbits Depending on the Sex-composition of the Groups, 2012. World Rabbit Congress, 10, Sharm El-Sheikh, Egypt, pp. 1003-1007.

Trocino, A., Xiccato, G., 2006. Animal welfare in reared rabbits: a review with emphasis on housing systems. World Rabbit Sci. 14, 77-93.
Trocino, A., Filiou, E., Tazzoli, M., Bertotto, D., Negrato, E., Xiccato, G., 2014. Behaviour and welfare of rabbits housed in cages and pens. Livest. Sci. 167, 305-314.

Van Praag, H., Kempermann, G., Gage, F.H., 2000. Neural consequences of environmental enrichment. Nat. Rev. Neurosci. 1, 191-198.

Van Zutphen, L.F., Fox, R.R., 1977. Strain differences in response to dietary cholesterol by JAX rabbits: correlation with esterase patterns. Atherosclerosis 28, 435-446.

Verga, M., Luzi, F., Carenzi, C., 2007. Effects of husbandry and management systems on physiology and behavior of farmed and laboratory rabbits. Horm. Behav. 52 122-129.

Vervaecke, H., De Bonte, L., Maertens, L., Tuyttens, F., Stevens, J.M.G., Lips, D., 2010. Development of hierarchy and rank effects in weaned growing rabbits (Oryctolagus cuniculus). World Rabbit Sci. 18, 139-149.

Von Holst, D., Hutzelmeyer, H., Kaetzke, P., Khaschei, M., Rödel, H.G., Schrutka, H., 2002. Social rank, fecundity and lifetime reproductive success in wild European rabbits (Oryctolagus cuniculus) Behav. Ecol. Sociobiol. 51, 245-254. 